\title{
28 Research Suare \\ Expansion of known skin microbes could aid skin health research
}

Collin Timm, Ph.D.

Kristin Loomis

William Stone

Thomas Mehoke

Bryan Brensinger

Matthew Pellicore

Philip Staniczenko

Curtisha Charles

Seema Nayak

David Karig

\section{Video Byte}

Keywords: skin microbes, skin health, microorganisms, Staphylococcus, Micrococcus, amino acids, steroids, lipids, sugars, personal care products, metabolic activities, human skin, Microbiome

Posted Date: June 23rd, 2020

DOI: https://doi.org/10.21203/rs.3.rs-37695/v1

License: (c) (1) This work is licensed under a Creative Commons Attribution 4.0 International License. Read Full License 


\section{Abstract}

The skin micro-environment varies across the body. But one thing that remains constant is the presence of microorganisms that affect skin health. In a recent study, researchers gathered more than 800 organisms from 3 body sites of 17 individuals. Analyses revealed $30+$ bacterial genera and $14+$ fungal genera, with the most prevalent being Staphylococcus and Micrococcus bacteria. Further tests showed that the collected microbes had the capacity to break down a variety of compounds. including amino acids, steroids, lipids, and sugars, as well as compounds derived from personal care products. This collection of micro-organisms represents a valuable resource for skin microbiome research, with the potential for developing novel therapeutics and for gaining insight into the metabolic activities of the skin microbiota. 